\title{
Effectiveness of elastic band-type ankle-foot orthoses on postural control in poststroke elderly patients as determined using combined measurement of the stability index and body weight-bearing ratio
}

This article was published in the following Dove Press journal:

Clinical Interventions in Aging

13 November 2015

Number of times this article has been viewed

\author{
Jong Hyun Kim \\ Woo Sang Sim \\ Byeong Hee Won \\ Usability Evaluation Technology \\ Center, Advanced Biomedical and \\ Welfare R\&D Group, Korea Institute \\ of Industrial Technology, Cheonan-si, \\ Chungcheongnam-do, South Korea
}

Correspondence: Byeong Hee Won Usability Evaluation Technology Center, Advanced Biomedical and Welfare R\&D Group, Korea Institute of Industrial Technology, 89, Yangdaegiro-gil, Ipjang-myeon, Seobuk-gu, Cheonan-si, Chungcheongnam-do 33I-822,

South Korea

Tel +82 I0 373। 8090

Fax +82505 731 8091

Email bhwon@kitech.re.kr
Purpose: Poor recovery of postural stability poststroke is the primary cause of impairment in activities and social participation in elderly stroke survivors. The purpose of our study was to experimentally evaluate the effectiveness of our new elastic ankle-foot orthosis (AFO), compared to a traditional AFO fabricated with hard plastic, in improving postural stability in elderly chronic stroke survivors.

Patients and methods: Postural stability was evaluated in ten chronic stroke patients, $55.7 \pm 8.43$ years old. Postural stability was evaluated using the standardized methods of the Biodex Balance System combined with a foot pressure system, under three experimental conditions, no AFO, rigid plastic AFO, and elastic AFO (E-AFO). The following dependent variables of postural stability were analyzed: plantar pressure under the paretic and nonparetic foot, area of the center of balance (COB) and \% time spent in each location, distance traveled by the COB away from the body center, distance traveled by the center of pressure, and calculated index of overall stability, as well as indices anterior-posterior and medial-lateral stability.

Results: Both AFO designs improved all indices of postural stability. Compared to the rigid plastic AFO, the E-AFO produced additional positive effects in controlling anterior-posterior body sway, equalizing weight bearing through the paretic and nonparetic limbs, and restraining the displacement of the center of pressure and of the COB.

Conclusion: Based on our outcomes, we recommend the prescription of E-AFOs as part of a physiotherapy rehabilitation program to promote recovery of postural stability poststroke. When possible, therapeutic outcomes should be documented using the Biodex Balance System and foot pressure system, as used in our study, to provide evidence needed to support the development of a larger controlled trial to generate high-quality evidence on the effectiveness of E-AFOs.

Keywords: ankle-foot orthoses, usability test, hemiplegia, Biodex Balance System, postural stability test

\section{Introduction}

Stroke is a leading cause of disability, particularly in older individuals. ${ }^{1-3}$ The incidence of stroke is greater than twice that for both men and women after the age of 55 years and continues to increase significantly every decade after this, with $65 \%$ of all strokes occurring in adults over the age of 65 years. ${ }^{1,4,5}$ Compared to younger adults, older individuals commonly have poorer functional outcomes poststroke, including more 
significant residual impairments in postural control and gait, ${ }^{3,6}$ even after adjusting for baseline differences in age-related risk factors for stroke and other comorbidities. ${ }^{3,7-9}$ This is an important public health issue as 15 million individuals or more sustain a stroke annually and 5 million survivors are left with permanent disability. ${ }^{10}$ Stroke is commonly associated with impairments in sensory, motor, cognitive, and emotional function, which can lead to restrictions in individuals' ability to perform basic activities of daily living (ADLs). ${ }^{11,12}$ It is estimated that $33 \%-42 \%$ of elderly stroke survivors still require assistance for ADLs 6 years poststroke. ${ }^{13}$

Of all sensorimotor disabilities poststroke, impairments in postural control have the greatest impact on independence in ADLs and gait. ${ }^{14-17}$ In fact, among the many biological and functional characteristics that influence recovery poststroke, impairment in postural control is the best predictive indicator of return to independent living. ${ }^{18}$ The extent of impairment in postural control also has the correlation $\left(r_{\mathrm{p}}=0.70\right)$ to person-perceived disability following discharge from rehabilitation programs. ${ }^{19}$ From an accident risk management perspective, the extent of impairment in postural control is also a determinant factor in the incidence of falls and fallrelated injuries poststroke. ${ }^{3}$ Therefore, rapid and optimal improvement of postural control in elderly stroke survivors is essential to promoting independence, social participation, and general health and well-being. Consequently, improvement of postural control has become an important goal of rehabilitation, particularly for patients presenting with both motor and sensory deficits. ${ }^{20-22}$

While a general physiotherapy stroke rehabilitation program can facilitate recovery of postural control to a certain degree, ${ }^{23}$ the majority of elderly patients require an ankle-foot orthosis (AFO) to manage residual impairment in postural control. AFOs improve postural stability by controlling the motion of the lower leg over the ankle, restraining the displacement of the body center of pressure (COP) under the foot, providing sensory feedback to facilitate muscle activity around the ankle joint, and facilitating overall weight bearing through the paretic limb. ${ }^{24-26}$ Through their facilitation of postural control, AFOs have also been shown to improve gait. $^{26}$

Despite the demonstrated evidence of AFOs for ameliorating postural control and gait poststroke, as well as lowering the risk of falls and fall-related injuries, the usability and wearability of AFOs are limited by the rigid plastic commonly used to form AFOs, which is uncomfortable and is associated with a high incidence of skin problems, particularly in elderly patients. Consequently, elderly patients are reluctant to use
AFOs, despite the possible benefits of AFOs in ameliorating their independence and overall quality of life. ${ }^{27-32}$ To address this issue of usability and wearability of AFOs, we developed a new AFO fabricated using soft elastic material. The aim of our study was to experimentally evaluate the effectiveness of our new elastic AFO, compared to a traditional AFO fabricated with rigid plastic, in improving postural control in elderly patients poststroke. Postural control was evaluated using the standardized Biodex Balance System to quantify the center of balance $(\mathrm{COB})^{33}$ under three experimental conditions: no AFO (N-AFO); wearing rigid, plastic AFO (P-AFO); and wearing our elastic AFO (E-AFO).

\section{Methods \\ Ankle-foot orthoses}

AFOs are the most commonly used orthoses, making up $\sim 26 \%$ of all orthoses provided in the United States. ${ }^{36}$ An AFO is an external device applied to the lower leg, ankle, and foot to improve lower limb function, posture control, and gait by controlling the alignment and motion of the foot and ankle, compensating for muscle weakness, increasing weight bearing through the paretic limb, redistributing ground reaction forces over the plantar surface of the foot, reducing pain by distributing weight bearing over a larger surface area, correcting flexible deformities and preventing progression of fixed deformities, lowering the risk for ankle fracture resulting from fixed deformities of the ankle associated with high muscle stiffness and soft tissue contractures, and preventing foot drop during the swing phase of gait. ${ }^{37,38}$ The P-AFOs used in the experiment were the common, plastic AFOs that showed improvements in heel sensory input function and wearability by using a simplified structure. Recently, this device has commonly been prescribed for poststroke elderly patients in chronic stage of recovery. Despite the above-mentioned improvements, P-AFOs still have certain problems, such as wearing discomfort, muscle stiffness, and limited mobility of the ankle joint due to the rigid plastic material. Therefore, considering the problems associated with P-AFOs, E-AFOs were developed using flexible, elastic fabric material. The use of this material in E-AFOs helped avoid the problems with wearability or limited ankle joint mobility, as encountered with P-AFOs. Four types of AFOs such as flexible AFOs, anti-talus AFOs, rigid AFOs and tamarack flexure joint were classified by the International Red Cross. ${ }^{39}$ The characteristics of the E-AFO, which is being evaluated in this study, are included under the category of flexible AFOs, and those of the P-AFO under the category of rigid AFOs. Both E-AFOs and P-AFOs provide dorsiflexion 
assist through stabilization of the subtalar joint, with the main difference between the two AFOs being in the rigidity of the control provided due to differences in the stiffness of the material.

\section{Participants}

The descriptive characteristics of the participants are listed in Table 1. The study group included ten elderly, poststroke patients, with a mean age of $55.7 \pm 8.43$ years, height: $167 \pm 6.54 \mathrm{~cm}$, weight: $67.8 \pm 11.66 \mathrm{~kg}$, and body mass index: $24.2 \pm 3.09 \mathrm{~kg} / \mathrm{m}^{2}$. Of these ten patients, nine presented with impairments in lower limb sensation, five had experienced a fall, and eight had been prescribed and used an AFO, but were no longer using their AFO at the time of the study. Reasons for not using their AFO included "poor fit", difficulty donning, and no apparent benefit to standing, walking, and ADLs.

Participants were selected based on the recommendation of the medical staff of the National Rehabilitation Center of South Korea, and all the patients have similar level of ankle-foot ability such as spasticity, muscle weakness, and decreased range of motion. This study received approval from the Public IRB designated by Ministry of Health \& Welfare, South Korea. All patients participated in the experiment after signing a participation agreement.

\section{Experimental design}

This study is a crossover design, with participants serving as their own control. Postural stability was evaluated using the Biodex Balance System (Biodex Medical Systems, Shirley, NY, USA; Figure 1A). The standardized balance test was performed under three experimental conditions: N-AFO, P-AFO, and E-AFO. A plantar foot pressure system (Pedar X_Insole-type, Novel GmbH, Munich, Germany; Figure 1B) was used in addition to the balance system in order to measure the magnitude and location of the plantar pressure force used to determine weight bearing through each of the lower limbs.

The insole pressure sensor system was used to record plantar foot pressure, with measures communicated wirelessly to the recording system to synchronize foot pressure with balance platform data. The plantar sensor system consisted of 256 pressure sensors, and the force under each sensor was geometrically combined to provide the resultant location and magnitude $(\mathrm{N})$ of the plantar pressure force. The displacement of the COP was calculated by summing the distance from each frame, recorded at $50 \mathrm{~Hz}$ during the length of the trial, based on the local coordinate $(x, y)$ system to calculate the direction of displacement.

\section{Experimental procedures}

Prior to data recording, the descriptive variables (age, height, weight, body mass index) were recorded. For the standardized test, participants were asked to stand on the balance platform, with their feet shoulder width apart and straddling the midline of the platform, to assume a comfortable position, and to look straight ahead. Facilitators were used to demonstrate the experimental task. The coordinates of the foot position were recorded to maintain a consistent foot position across all three experimental conditions. ${ }^{33,34}$ Participants completed two baseline postural stability tests, wearing their own shoes with the plantar foot pressure sensory attached to the sole. Following baseline measures, participants completed the postural stability test under each of the three experimental conditions, N-AFOs, P-AFOs, and E-AFOs, and the same content regarding the experimental method was provided to all the participants. Three trials were completed for each condition.

\section{Data acquisition and analysis}

The Biodex Balance System, used to assess postural stability, consists of a movable balance platform that provides up to

Table I Descriptive characteristics of study group

\begin{tabular}{|c|c|c|c|c|c|c|}
\hline Participants & $\begin{array}{l}\text { Sex/age } \\
\text { (years) }\end{array}$ & $\begin{array}{l}\text { Time since } \\
\text { stroke (months) }\end{array}$ & $\begin{array}{l}\text { Daily use } \\
\text { of AFOs }\end{array}$ & $\begin{array}{l}\text { Paretic } \\
\text { side }\end{array}$ & $\begin{array}{l}\text { Positive history } \\
\text { of falls (yes/no) }\end{array}$ & Type of stroke \\
\hline I & $M / 52$ & 80 & No & Right & $\mathrm{N}$ & Ischemic \\
\hline 2 & $M / 74$ & 130 & No & Right & $Y$ & Ischemic \\
\hline 3 & $\mathrm{~F} / 62$ & 78 & No & Right & $Y$ & Hemorrhagic \\
\hline 4 & $M / 58$ & 92 & Partially & Right & $\mathrm{N}$ & Ischemic \\
\hline 5 & $M / 56$ & 19 & No & Right & $Y$ & Ischemic \\
\hline 6 & $M / 56$ & 129 & No & Left & $Y$ & Ischemic \\
\hline 7 & $M / 52$ & 125 & No & Left & $Y$ & Ischemic \\
\hline 8 & $M / 54$ & 68 & Partially & Left & $\mathrm{N}$ & Hemorrhagic \\
\hline 9 & $M / 4 I$ & 43 & Constantly & Left & $\mathrm{N}$ & Hemorrhagic \\
\hline 10 & $M / 52$ & 91 & Constantly & Left & $N$ & Hemorrhagic \\
\hline
\end{tabular}

Abbreviations: AFO, ankle-foot orthosis; $M$, male; $Y$, yes; N, no; F, female. 


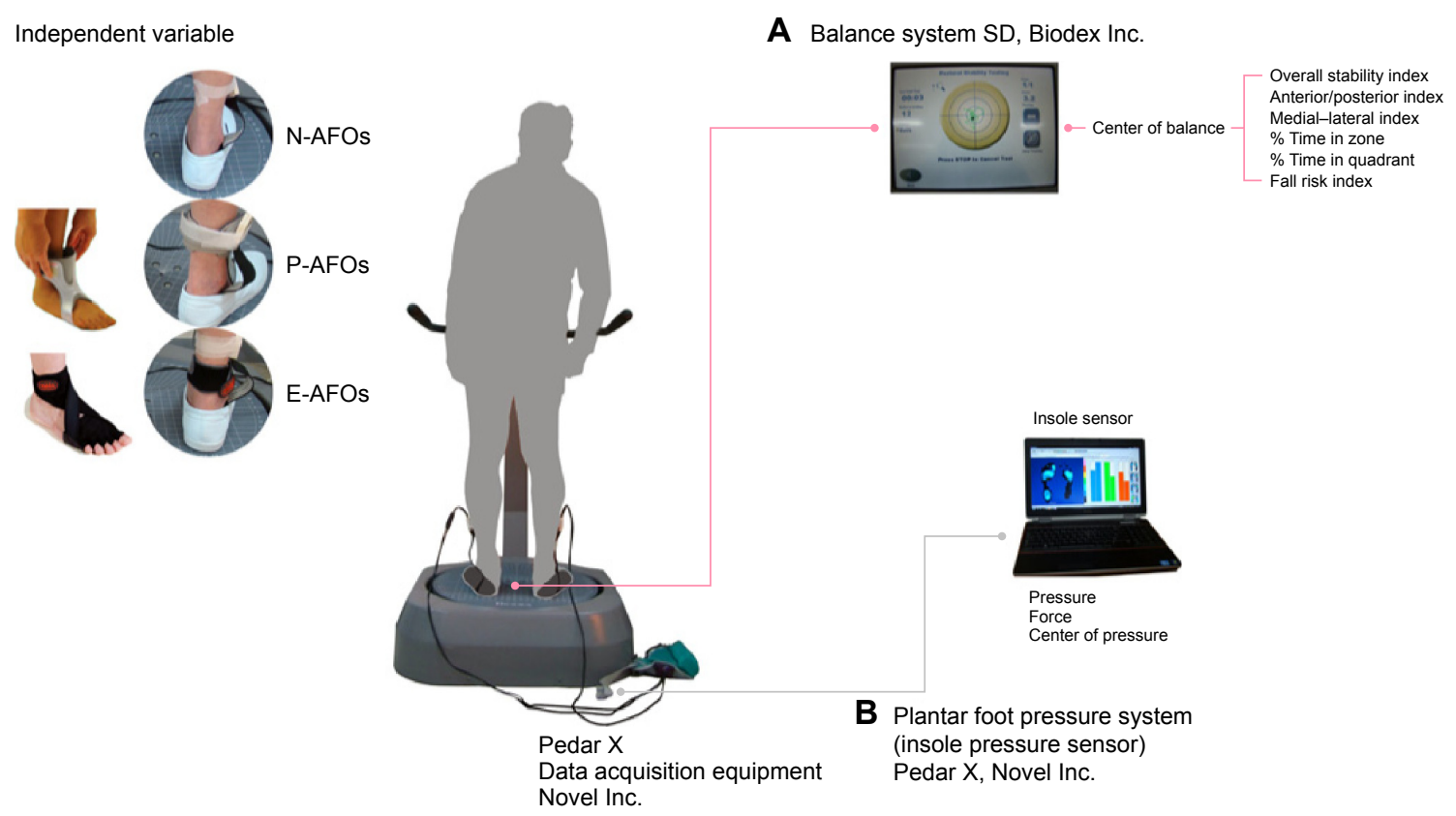

Figure I Experimental set-up: (A) the Biodex Balance System and (B) a plantar foot pressure system.

Abbreviations: AFOs, ankle-foot orthoses; N-AFOs, no AFOs (bare foot); P-AFOs, hard plastic-type AFOs; E-AFOs, elastic band-type AFOs by fabric material; SD, Static and Dynamic.

$20^{\circ}$ of surface tilt over a $360^{\circ}$ range of motion. The movable balance platform includes coordinate lines to standardize foot position on the platform and a sensing mat to record the position and displacement of the COB. The test includes 12 levels of graded postural stability. Following recommendations from previous studies and the manual for standardized testing, the anterior-posterior and medial-lateral stability scores (anterior-posterior stability index [APSI] and medial-lateral stability index [MLSI]) were recorded and geometrically combined to yield the overall stability index (OSI); the calculation of these indices is shown in Figure 2. The anterior-posterior index represents the distance of movement of the calculated COB along the sagittal plane and controlled by ankle plantar- and dorsiflexion, while the medial-lateral index represents the distance of $\mathrm{COB}$ movement along the frontal plane position, controlled by motions of inversion and eversion. ${ }^{40}$ The OSI represents the variance in $\mathrm{COB}$ displacement across all directions of platform motion and is compared to normal reference values to assess the risk of falls. ${ }^{33-35} \mathrm{~A}$ high stability index score is indicative of poor postural stability.

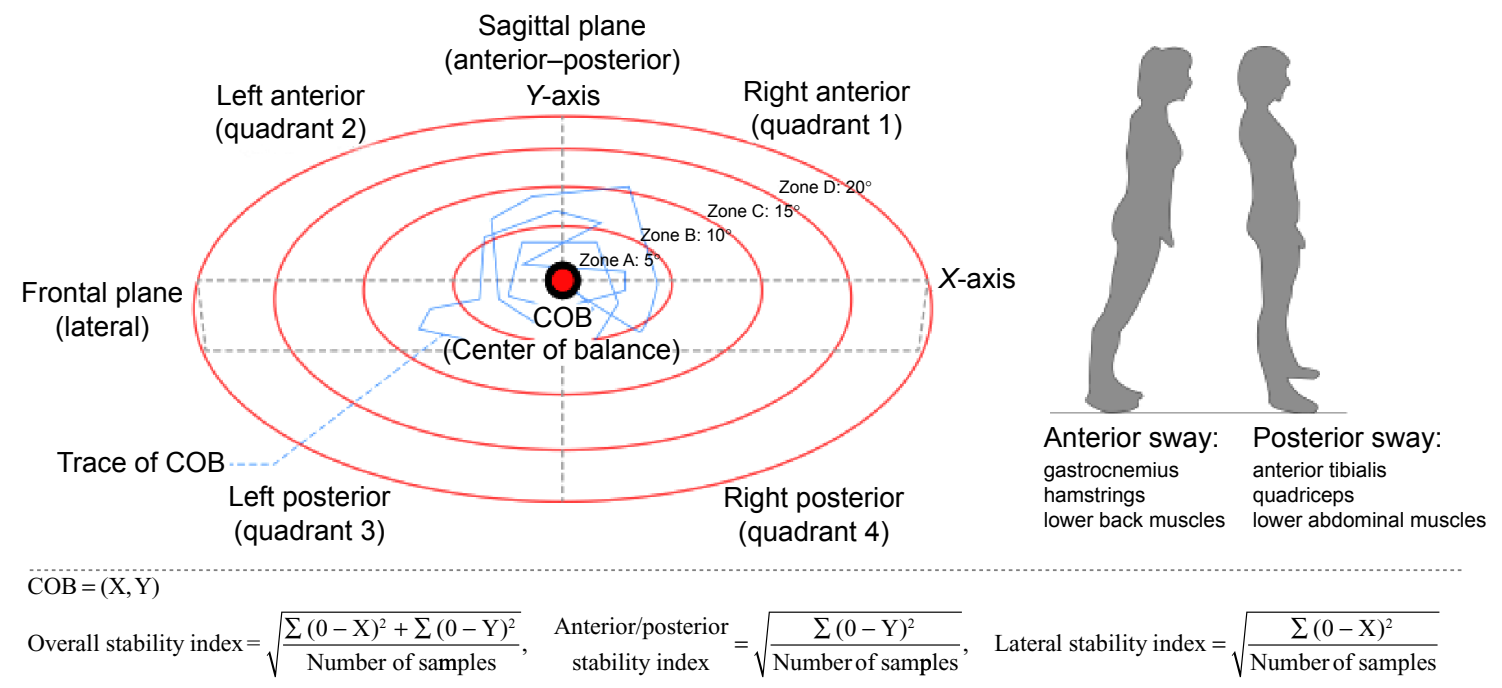

Figure 2 Data analysis for the Biodex Balance System. Note: Data from Biodex Medical Systems, Inc. ${ }^{33}$ 
The following dependent variables were used to compare the effects of the P-AFO and E-AFO on postural stability: OSI, APSI, MLSI, magnitude and location of the plantar surface force, location of the $\mathrm{COB}$, and $\%$ time spent in each of the locations. Location of $\mathrm{COB}$ was quantified using the standard methods of the balance system. Namely, the balance area was subdivided into four quadrants, an anterior and posterior quadrant under each foot. The distance of the COB from the center of the body was also calculated using the standardized zones A-D defined in the system, where each zone represents an increment of $5^{\circ}$ in tilt of the platform, from $5^{\circ}$ in zone $\mathrm{A}$ to a maximum $20^{\circ}$ in zone $\mathrm{D}$. The percent (\%) of time in each quadrant and zone over the trial was calculated (Figure 2).

\section{Statistical analysis}

Each variable was averaged over three complete trials of the postural stability test, with the mean used for statistical analyses. Participants were classified according to their affected side into a right and a left paretic side. ${ }^{40}$ A multivariate analysis was used to identify significant main effects of paretic side and AFO type. Individual effects across condition and AFO type were evaluated using a repeated measures analysis of variance (ANOVA). Where main effects were identified, follow-up post hoc comparisons (Tukey's honest significant difference) were performed. The probability associated with a type I error was set at 0.05 for all observations. All statistical analyzes were performed using SPSS, Version 12.0.

\section{Results}

\section{Result of postural stability}

The postural indices (OSI, APSI, and MLSI) are reported in Table 2 and shown in Figure 3. There was a significant lowering of all postural indices with both AFO types compared to the N-AFO condition, with AFOs producing a reduction of $\geq 1$ in the OSI, APSI, and MLSI scores. Effects of AFO on postural indices were comparable for the P-AFO and E-AFO.

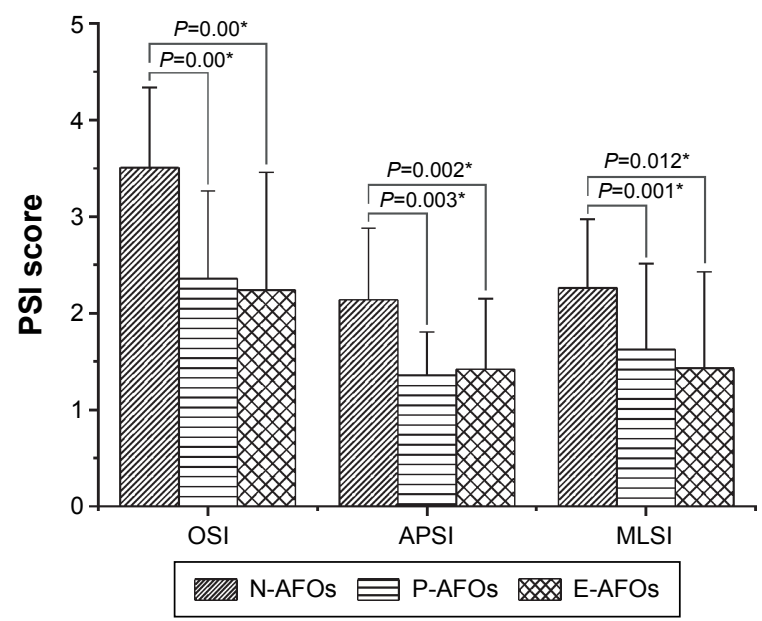

Figure 3 Result of postural stability index.

Notes: $* P<0.05$, PSl's formula.

Abbreviations: PSI, postural stability index; OSI, overall stability index; APSI, anterior/posterior stability index; $\mathrm{MLSI}$, medial/lateral stability index; AFOs, anklefoot orthoses; N-AFOs, no AFOs (bare foot); P-AFOs, hard plastic-type AFOs; E-AFOs, elastic band-type AFOs by fabric material.

The location of the COB within the four quadrants of the balance platform, and the related \% time spent in each quadrant, is shown in Figure 4. The first analysis compared the area visited by the $\mathrm{COB}$ under the paretic leg, normalized to the area under the nonparetic leg, to identify effects of paretic side and AFO type. The area of the COB was comparable for the right and left paretic side, with normalized areas of $36.4 \%$ and $33.6 \%$, respectively, under the N-AFO condition. Similarly, areas were comparable with the use of the E-AFO, with areas of $57.4 \%$ for the right and $51.6 \%$ for the left paretic side. However, P-AFO did produce an effect of paretic side, with areas of $39.4 \%$ for the right and $47.8 \%$ for the left paretic side.

Analysis of the $\%$ time of the COB spent in each quadrant indicated a significantly larger proportion of time spent on the nonparetic leg with N-AFO. For the nonparetic leg, the $\%$ time reflected a normal sway pattern, with a greater proportion of time spent in the posterior quadrant. This pattern was evident for the nonparetic limb as well but with very

Table 2 Result of postural stability index

\begin{tabular}{llll}
\hline PSI score & N-AFOs, mean $( \pm$ SD) & P-AFOs, mean $( \pm$ SD) & E-AFOs, mean $( \pm$ SD) \\
\hline OSI & $3.51( \pm 0.83)$ & $2.36( \pm 0.91)$ & $2.24( \pm 1.22)$ \\
APSI & $2.14( \pm 0.74)$ & $1.36( \pm 0.45)$ & $1.42( \pm 0.73)$ \\
MLSI & $2.26( \pm 0.72)$ & $1.63( \pm 0.89)$ & $1.43( \pm 1.00)$ \\
\hline
\end{tabular}

Notes: Reference range for the OSI by age (forecasting age: PSI score): (17-35 years: 0.82-2.26), (36-53 years: 1.23-3.03), (54-7I years: 1.79-3.35), and (72-89 years: 1.90-3.50).

Abbreviations: PSI, postural stability index; AFO, ankle-foot orthoses; N-AFOs, no AFOs (bare foot); P-AFOs, hard plastic-type AFOs; E-AFOs, elastic band-type AFOs by fabric material; SD, standard deviation; OSI, overall stability index; APSI, anterior/posterior stability index; MLSI, medial/lateral stability index. 
Result of right hemiplegia patients $(n=5)$

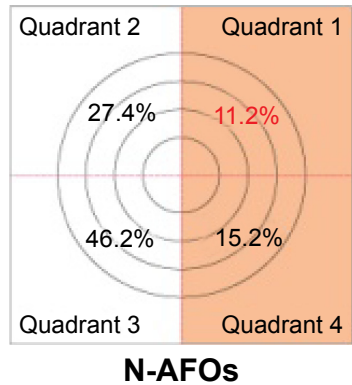

Result of left hemiplegia patients $(n=5)$

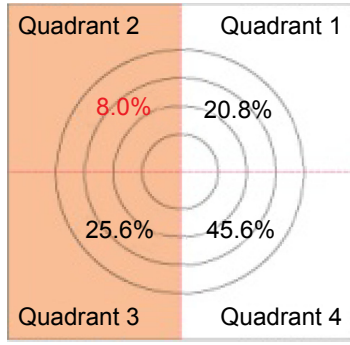

$\mathrm{N}-\mathrm{AFOs}$

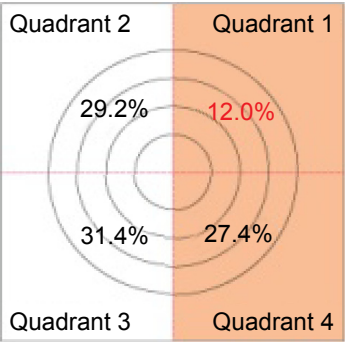

P-AFOs
Orange region: paretic side

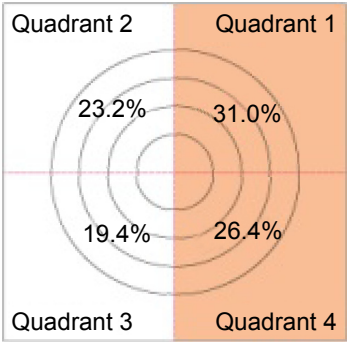

E-AFOs

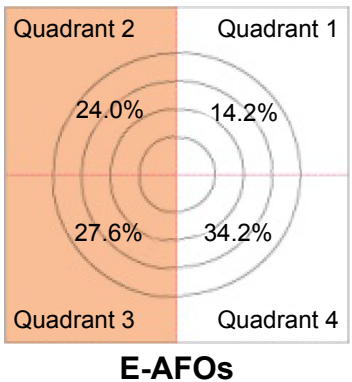

Figure 4 Result of time in quadrant (unit: \%).

Note: $\%$ (time in quadrant) = time stayed in quadrant/total run time $\times 100$. The font in red is the anterior quadrant for the paretic limb.

Abbreviations: AFOs, ankle-foot orthoses; N-AFOs, no AFOs (bare foot); P-AFOs, hard plastic-type AFOs; E-AFOs, elastic band-type AFOs by fabric material.

little time spent in the anterior quadrant. Both the P-AFO and the E-AFO produced a significant increase in the \% time spent on the paretic lower limb compared to the N-AFO condition, with the increase in $\%$ time being largest for the E-AFO. In addition to increasing the \% time weight bearing on the paretic lower limb, the E-AFO group also showed increased weight-bearing time in the anterior quadrant on the paretic limb.

The location and time spent in each zones (A-D) are shown in Figure 5. Under the N-AFO condition, the COB was located in the center of the platform $76.2 \%$ of the time and increase to $92.5 \%$ and $91.1 \%$ with the use of $\mathrm{P}-\mathrm{AFO}$ and E-AFO, respectively. With use of the E-AFO, the excursion of the $\mathrm{COB}$ did increase to zone $\mathrm{C}$ for one subject for $8 \%$ of the time.

\section{Result of plantar foot pressure}

The plantar pressure under the paretic foot across the three experimental conditions is shown in Figure 6. There was a significant reduction in plantar pressure on the paretic and nonparetic side under the N-AFO condition, with $56 \%$ reduction in total plantar pressure on the paretic

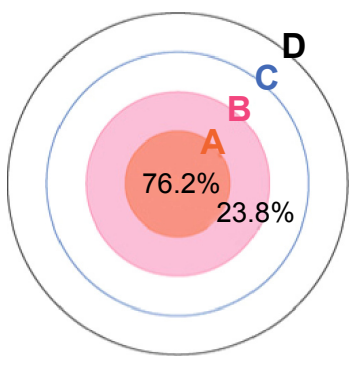

N-AFOs

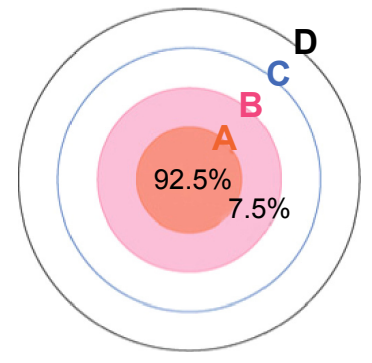

P-AFOs

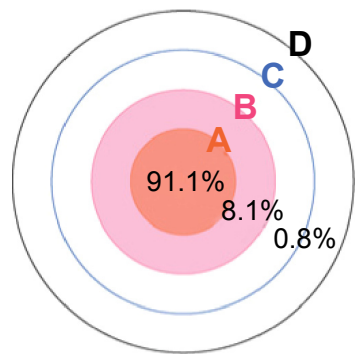

E-AFOs

Figure 5 Result of time in zone (unit: \%).

Notes: $\%$ (time in zone) $=$ time within zone/total run time $\times 100$, Zone A: tilt degree $<5^{\circ}$, Zone B: tilt degree $<10^{\circ}$, Zone C: tilt degree $<15^{\circ}$, and Zone $\mathrm{D}$ : tilt degree $<20^{\circ}$. Abbreviations: AFOs, ankle-foot orthoses; N-AFOs, no AFOs (bare foot); P-AFOs, hard plastic-type AFOs; E-AFOs, elastic band-type AFOs by fabric material. 


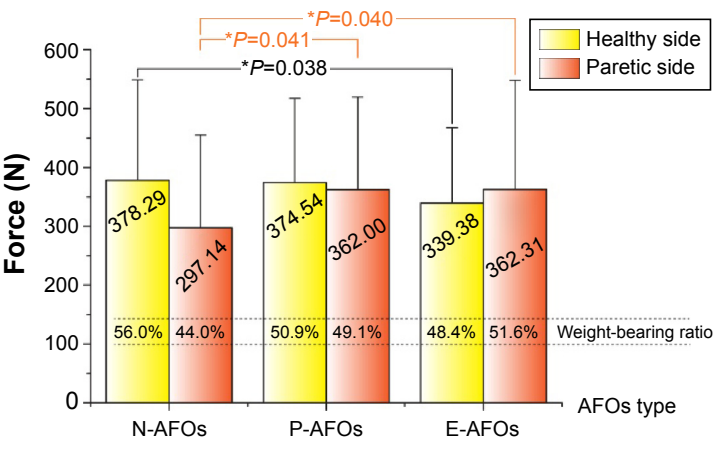

Figure 6 Result of force and weight bearing by AFOs type. Note: $* P<0.05$.

Abbreviations: AFOs, ankle-foot orthoses; N-AFOs, no AFOs (bare foot); P-AFOs, hard plastic-type AFOs; E-AFOs, elastic band-type AFOs by fabric material.

side. P-AFO increased weight bearing on the paretic lower limb from $297.12 \mathrm{~N}$ with $\mathrm{N}-\mathrm{AFO}$ to $362 \mathrm{~N}$ with P-AFO, to yield a comparable plantar pressure between the two limbs. Plantar pressure similarly increased to $362 \mathrm{~N}$ with the E-AFO. In addition, the E-AFO lowered the plantar pressure on the nonparetic limb from $378 \mathrm{~N}$ to $339 \mathrm{~N}$, improving the paretic-to-nonparetic weight-bearing ratio to $51.6 \%$.

The distance traveled by the COP for the three experimental conditions are shown in Figure 7. For all three experimental conditions, the distance traveled by the COP was larger for the paretic limb, with values of 1,372.9 mm for the nonparetic side and $1,400 \mathrm{~mm}$ for the paretic side with N-AFO, $794.8 \mathrm{~mm}$ and $856.0 \mathrm{~mm}$, respectively, with P-AFO, and $794.3 \mathrm{~mm}$ and $865.0 \mathrm{~mm}$, respectively, with E-AFO. While not correcting this between-limb difference in COP displacement, the E-AFO was effective in restraining the overall distance of travel of the COP, which is an important variable of stability.

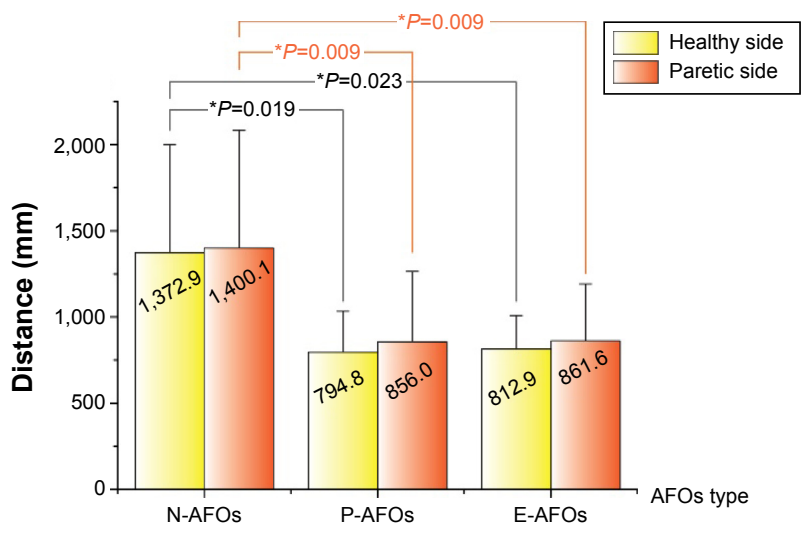

Figure 7 Result of COP's distance by AFOs. Note: $* P<0.05$.

Abbreviations: COP, center of pressure; AFOs, ankle-foot orthoses; N-AFOs, no AFOs (bare foot); P-AFOs, hard plastic-type AFOs; E-AFOs, elastic band-type AFOs by fabric material.

\section{Discussion}

Outcomes of our study confirm prior evidence of a positive effect of AFOs in improving postural stability and weight bearing through the paretic limb. In the N-AFO condition, the mean OSI of our study group was $3.51 \pm 0.83$, a value that is comparable to the stability predicted for an 89-yearold individual. ${ }^{33-35}$ Considering the mean age of our study group of 55.7 \pm 8.43 , an OSI ranging between 1.79 and $\sim 2.0$ would be expected. ${ }^{34,35}$ Based on these reference values, both the P-AFO and the E-AFO improved the OSI to within normal age reference limits, with values of $2.36 \pm 0.91$ and $2.24 \pm 1.22$, respectively. ${ }^{34,35}$ This represents an overall improvement in stability of $\sim 30 \%$. Overall, the results were comparable for both P-AFO and E-AFO, although the $\mathrm{E}-\mathrm{AFO}$ did normalize the weight-bearing ratio between the two limbs to a greater extent, through a modulating effect on the nonparetic side. The E-AFO also exerted a greater restraint on the displacement of the COP. Our results further provide evidence of the effectiveness of AFOs in improving anterior-posterior and medial-lateral stability of the foot and ankle. Analysis of the location of the COB and \% time in the quadrant positions of the balance platform provides an assessment of the sway pattern of the body that reflects the stabilizing moments of force exerted through the lower leg muscle active about ankle joint. ${ }^{24}$ In the N-AFO condition, the $\%$ time in the anterior quadrant, associated with an anterior sway of the body, was low in patients with right (11.2\%) and left $(8.0 \%)$ paresis. Both AFO types improved control of anterior body sway, with the E-AFO being most effective in increasing $\%$ time of the $\mathrm{COB}$ in the anterior quadrant for the paretic limb. We hypothesize that selective effectiveness of the E-AFO in improving control of anterior-posterior body sway during standing likely results from the facilitating effects of the elastic material in allowing controlled, lowamplitude, mobility around the ankle joint and facilitating the activation of the ankle musculature, two parameters that have been associated with improved gait poststroke. ${ }^{41,42}$ We, therefore, anticipate that the improvements in postural stability afforded by the E-AFO would translate to improved gait ability; however, these benefits will need to be confirmed in future studies.

An important outcome of our study is the demonstrated effectiveness of the E-AFO in normalizing bilateral weight bearing. Similar to the P-AFO, the E-AFO did increase the magnitude of plantar pressure under the paretic foot. However, the E-AFO also modulated weight bearing on the nonparetic side, an effect not apparent with the P-AFO, resulting in comparable weight bearing on both sides. This 
bilateral effect would be important in normalizing side-toside weight-shifting patterns, an effect that will need to be formally evaluated in subsequent research. In addition to facilitating weight bearing on the paretic limb, AFOs produced a significant effect on the control of the COP, with the E-AFO restraining the displacement of the COP to a greater extent than the P-AFO. This effectiveness of AFOs in restraining the displacement of the COP is in agreement with results from the previous studies identifying positive effects of AFOs in stabilizing postural control. ${ }^{43-46}$ The improvements in COP control significantly correlated with lower OSI scores, with correlations of $r_{\mathrm{p}}=0.852(P<0.001)$ on the nonparetic side and $r_{\mathrm{p}}=0.891(P<0.001)$ on the paretic side. In addition to demonstrating the effectiveness of AFOs on COP control, these high correlations indicate the reliability of using the Biodex Balance System plantar foot pressure systems to evaluate the effectiveness of AFOs, as well as postural retraining programs.

The evidence of effectiveness of AFOs, and the E-AFO specifically, in our study must be considered within the limitations of the study. Participants had a mean age of $\sim 55$ years and are in the chronic phase of stroke recovery (ie, $>1$ year poststroke). The short-term effectiveness of E-AFO and outcomes on gait cannot be evaluated within the context of our study.

\section{Conclusion}

Poor recovery of postural stability poststroke is a primary cause of impairment in activities and social participant in the elderly. ${ }^{1-3}$ Prescription of AFOs is an effective intervention to improve postural stability, lower the risk of falls, and promote participation in ADLs of these patients. ${ }^{3}$ Use of an E-AFO can promote increased use of AFOs among the elderly, improving both fit and wearability, as well as providing specific improvement in postural control that would likely translate to improved gait abilities. We anticipate that the documented effects on postural control would lower the risk of falls; this will need to be evaluated in future research. Based on our outcomes, we do recommend that E-AFOs be used in the rehabilitation of elderly stroke patient and that outcomes be documented using the Biodex Balance System and foot pressure system to provide evidence needed to support the development of a larger controlled trial.

\section{Acknowledgment}

This study was supported by the Korea Institute of Industrial Technology.

\section{Disclosure}

The authors report no conflicts of interest in this work.

\section{References}

1. Lloyd-Jones D, Adams R, Carnethon M, et al; American Heart Association Statistics Committee and Stroke Statistics Subcommittee. Heart disease and stroke statistics - 2009 update: a report from the American Heart Association Statistics Committee and Stroke Statistics Subcommittee. Circulation. 2009;119:480-486.

2. Murray CJL, Lopez AD. Alternative projections of mortality and disability by cause 1990-2020: global burden of disease study. Lancet. 1997;349:1498-1504.

3. Pinter MM, Brainin M. Rehabilitation after stroke in older people. Maturitas. 2012;71:104-108.

4. Rothwell PM, Coull AJ, Silver LE, et al; Oxford Vascular Study. Population-based study of event-rate, incidence, case fatality, and mortality for all acute vascular events in all arterial territories (Oxford Vascular Study). Lancet. 2005;366:1773-1783.

5. Tuomilehto J, Mahonen M, Cinzia S. Basic epidemiology of stroke and risk assessment. In: Brainin M, Heiss WD, editors. Textbook of Stroke Medicine. Cambridge: Cambridge University Press; 2010:77-88.

6. Fonarow GC, Reeves MJ, Zhao X, Get With the Guidelines-Stroke Steering Committee and Investigators, et al. Age-related differences in characteristics, performance measures, treatment trends, and outcomes in patients with ischemic stroke. Circulation. 2010;121:879-891.

7. Kelly-Hayes M, Beiser A, Kase CS, Scaramucci A, D’Agostino RB, Wolf PA. The influence of gender and age on disability following ischemic stroke: the Framingham study. J Stroke Cerebrovasc Dis. 2003; 12:119-126.

8. Bhalla A, Grieve R, Tilling K, Rudd AG, Wolfe CD. Older stroke patients in Europe: stroke care and determinants of outcome. Age Ageing. 2004;33:618-624.

9. Kammersgaard LP, Jorgensen HS, Reith J, Nakayama H, Pedersen PM, Olsen TS. Short- and long-term prognosis for very old stroke patients: the Copenhagen Stroke Study. Age Ageing. 2004;33:149-154.

10. World Health Organization. Global Burden of Stroke. Available from: http://www.who.int/cardiovascular_diseases/en/cvd_atlas_15_burden_stroke.pdf. Accessed January 22, 2009.

11. Geurts AC, de Haart M, van Nes IJ, Duysens J. A review of standing balance recovery from stroke. Gait Posture. 2005;22:267-281.

12. Hochstenbach J, Donders R, Mulder T, van Limbeek J, Schoonder Waldt H. Long-term outcome after stroke: a disability-orientated approach. Int J Rehabil Res. 1996;19:189-200.

13. Feigin VL, Barker-Collo S, McNaughton H, Brown P, Kerse N. Longterm neuropsychological and functional outcomes in stroke survivors: current evidence and perspectives for new research. Int $J$ Stroke. 2008;3:33-40.

14. Bohannon RW, Leary KM. Standing balance and function over the course of acute rehabilitation. Arch Phys Med Rehabil. 1995;76:994-996.

15. Fong KN, Chan CC, Au DK. Relationship of motor and cognitive abilities to functional performance in stroke rehabilitation. Brain Inj. 2001;15:443-453.

16. Keenan MA, Perry J, Jordan C. Factors affecting balance and ambulation following stroke. Clin Orthop. 1984;182:165-171.

17. Sandin KJ, Smith BS. The measure of balance in sitting in stroke rehabilitation prognosis. Stroke. 1990;21:82-86.

18. Lin JH, Hsieh CL, Hsiao SF, Huang MH. Predicting long-term care institution utilization among post-rehabilitation stroke patients in Taiwan: a medical centre-based study. Disabil Rehabil. 2001;23:722-730.

19. Desrosiers J, Noreau L, Rochette A, Bravo G, Boutin C. Predictors of handicap situations following post-stroke rehabilitation. Disabil Rehabil. 2002;24:774-785.

20. Forster A, Young J. Incidence and consequences of falls due to stroke: a systematic inquiry. BMJ. 1995;311:83-86.

21. Nyberg L, Gustafson Y. Patient falls in stroke rehabilitation. A challenge to rehabilitation strategies. Stroke. 1995;26:838-842. 
22. Stoker Yates J, Min Lai S, Duncan P, Studenski S. Falls in communitydwelling stroke survivors: an accumulated impairments model. J Rehabil Res Dev. 2002;39:385-394.

23. Pollock A, Baer G, Pomeroy V, Langhorne P. Physiotherapy treatment approaches for the recovery of postural control and lower limb function following stroke. Cochrane Database Syst Rev. 2003; 1(1):CD001920.

24. Winter DA, Prince F, Frank JS, Powell C, Zabjek KF. Unified theory regarding $\mathrm{A} / \mathrm{P}$ and $\mathrm{M} / \mathrm{L}$ balance in quiet stance. J Neurophysiol. 1996; 75:2334-2343.

25. Chen CL, Yeung KT, Wang CH, Chu HT, Yeh CY. Anterior anklefoot orthosis effects on postural stability in hemiplegic patients. Arch Phys Med Rehabil. 1999;80:1587-1592.

26. Pomeroy VM, Evans B, Falconer M, Jones D, Hill E, Giakas G. An exploration of the effects of weighted garments on balance and gait of stroke patients with residual disability. Clin Rehabil. 2001; 15:390-397.

27. Pollock A, Baer G, Pomeroy V, Langhorne P. Physiotherapy treatment approaches for the recovery of postural control and lower limb function following stroke. Cochrane Database Syst Rev. 2007;1:CD001920.

28. Ferrarello F, Baccini M, Rinaldi LA, et al. Efficacy of physiotherapy interventions late after stroke: a meta-analysis. J Neurol Neurosurg Psychiatry. 2011;82:136-143.

29. Weerdestexn V, De Niet M, van Duijnhoven HJ, Geurts AC. Falls in individuals with stroke. J Rehabil Res Dev. 2008;45:1195-1213.

30. Saunders DH, Greig CA, Mead GE, Young A. Physical fitness training for stroke patients. Cochrane Database Syst Rev. 2009;4:CD003316.

31. Barcly-Goddard RE, Stevenson TJ, Poluha W, Moffatt M, Taback SP. Force platform feedback for standing balance training after stroke. Cochrane Database Syst Rev. 2004;18:CD004129.

32. Van Peppen RP, Kortsmit M, Lindeman E, Kwakkel G. Effects of visual feedback therapy on postural control in bilateral standing after stroke: a systematic review. J Rehabil Med. 2006;38:3-9.

33. Biodex Medical Systems, Inc. Balance System SD Operation/Service Manual. Shirley, NY: Biodex Medical Systems, Inc; 2011.

34. Cakar E, Durmus O, Tekin L, Dincer U, Kiralp MZ. The ankle-foot orthosis improves balance and reduces fall risk of chronic spastic hemiparetic patients. Eur J Phys Rehabil Med. 2010;46:363-368.
35. Cakar E, Dincer U, Kiralp MZ, et al. Jumping combined exercise programs reduce fall risk and improve balance and life quality of elderly people who live in a long-term care facility. Eur J Phys Rehabil Med. 2010;46:59-67.

36. Whiteside S, Allen MJ, Bick JA, et al. Practice Analysis of Certified Practitioners in the Disciplines of Orthotics and Prosthetics. Alexandria, VA: American Board for Certification in Orthotics and Prosthetics, Inc.; 2007.

37. Lower Limb Orthotics. Available from: http://emedicine.medscape. com/article/314838-overview. eMedicine from WebMD. Accessed September 15,2010 .

38. Kolata G. Close Look at Orthotics Raises a Welter of Doubts; 2011. New York Times. Available from: http://www.nytimes.com/2011/01/18/ health/nutrition/18best.html?_r=1\&src=me\&ref=general. Accessed January 18, 2011.

39. ICRC AFO Manufacturing Guidelines. Available from: http://www. icrc.org/eng/assets/files/other/eng-afo-2010.pdf. Accessed October 6, 2014.

40. Sim WS, Won BH. Evaluation of balance ability of hemiplegic patients depending on the use of an elastic band-type ankle-foot orthosis. In: ACED; 2014.

41. Kobayashi T, Leung AK, Akazawa Y, Hutchins SW. The effect of varying the plantarflexion resistance of an ankle-foot orthosis on knee joint kinematics in patients with stroke. Gait Posture. 2013;37:457-459.

42. Perry J. Gait and Analysis. Normal and Pathological Function. Thorofare, NJ: Slack Inc.; 1992.

43. Walker C, Brouwer BJ, Culham EG. Use of visual feedback in retraining balance following acute stroke. Phys Ther. 2000;80:886-895.

44. Shumway-Cook A, Anson D, Haller S. Postural sway biofeedback: its effect on reestablishing stance stability in hemiplegic patients. Arch Phys Med Rehabil. 1988;69:395-400.

45. Lee MY, Wong MK, Tang FT. Clinical evaluation of a new biofeedback standing balance training device. J Med Eng Technol. 1996; 20:60-66.

46. Dault MC, de Haart M, Geurts AC, Arts IM, Nienhuis B. Effects of visual center of pressure feedback on postural control in young and elderly healthy adults and in stroke patients. Hum Mov Sci. $2003 ; 22: 221-236$
Clinical Interventions in Aging

\section{Publish your work in this journal}

Clinical Interventions in Aging is an international, peer-reviewed journal focusing on evidence-based reports on the value or lack thereof of treatments intended to prevent or delay the onset of maladaptive correlates of aging in human beings. This journal is indexed on PubMed Central, MedLine,

\section{Dovepress}

CAS, Scopus and the Elsevier Bibliographic databases. The manuscript management system is completely online and includes a very quick and fair peer-review system, which is all easy to use. Visit http://www.dovepress. com/testimonials.php to read real quotes from published authors. 